\title{
Unique associations of the Job Demand-Control- Support model subscales with leisure-time physical activity and dietary energy intake
}

\author{
Christopher G. BEAN ${ }^{1,2}$, Helen R. WINEFIELD ${ }^{2}$, Amanda D. HUTCHINSON ${ }^{3}$, \\ Charli SARGENT ${ }^{4}$ and Zumin $\mathrm{SHI}^{5,6}$ \\ ${ }^{1}$ Department of Public Health and Caring Sciences, Uppsala University, Sweden \\ ${ }^{2}$ School of Psychology, University of Adelaide, Australia \\ ${ }^{3}$ School of Psychology, Social Work and Social Policy, University of South Australia, Australia \\ ${ }^{4}$ Appleton Institute for Behavioural Science, Central Queensland University, Australia \\ ${ }^{5}$ Discipline of Medicine, University of Adelaide, Australia \\ ${ }^{6}$ Human Nutrition Department, College of Health Sciences, Qatar University, Qatar
}

Received October 30, 2017 and accepted June 29, 2018

Published online in J-STAGE August 2, 2018

\begin{abstract}
Leisure-time physical activity (LTPA) and dietary energy intake are two important health behaviours, which at too low or high levels respectively, are associated with overweight and obesity. This study explores associations between subscales of the Job Demand-Control-Support (JDCS) model, LTPA and dietary energy intake. A cross-sectional design sampled current employees $(N=433)$ from a South Australian cohort using a computer-assisted telephone interview and a self-completed food frequency questionnaire. In analyses adjusted for sex, age, and sociodemographic variables, higher levels of skill discretion were associated with increased odds for attaining sufficient physical activity $(\mathrm{OR}=2.45 ; 95 \% \mathrm{CI}=1.10-5.47)$. Higher levels of decision authority were associated with reduced odds $(\mathrm{OR}=0.43 ; 95 \% \mathrm{CI}=0.20-0.93)$ for being in the highest tertile of daily energy intake. Higher scores for coworker support were associated with increased odds (OR=2.20; 95\% $C I=1.15-4.23$ ) for being in the highest tertile of daily energy intake. These findings support the consideration of the individual JDCS subscales, since this practice may reveal novel associations with health behaviour outcomes, thereby presenting new opportunities to improve employee health and wellbeing.
\end{abstract}

Key words: Energy intake, Diet, Leisure-time physical activity, Obesity, Work stress

\section{Introduction}

High prevalence of overweight and obesity is a global phenomenon, and Australia has some of the highest record-

*To whom correspondence should be addressed.

E-mail: christopher.bean@pubcare.uu.se

(C)2019 National Institute of Occupational Safety and Health ed levels of these conditions ${ }^{1,2)}$. National data collected between $2014-15$ indicates $63.4 \%$ of Australian adults are overweight (body mass index; BMI 25.00-29.99) or obese $(\mathrm{BMI} \geq 30)^{3)}$. The energy balance hypothesis, specifically 'positive energy balance', is generally accepted as the biological mechanism that accounts for most overweight and obesity ${ }^{4}$. A positive energy balance, leading to excess weight gain and maintenance, occurs when energy intake is greater than energy expenditure over a sustained period 
of time. The nature of the positive energy balance may be related to either excess energy intake (e.g., consuming too much food), or insufficient expenditure (e.g., too little physical activity), or a combination of these behaviours ${ }^{4,5}$.

Leisure-time physical activity (LTPA) is a useful type of physical activity to consider since recognised guidelines outlining recommended levels have been published, and it may also be more easily modifiable than other types of physical activity such as occupational-related physical activity, which may be limited by job nature or other constraints $^{6}$. The World Health Organization ${ }^{7)}$ recommend $\geq 150 \mathrm{~min}$ (or $\geq 75 \mathrm{~min}$ vigorous intensity, or equivalent combination) of LTPA per wk for adults. Similarly, the National Physical Activity Guidelines for Australian adults ${ }^{8)}$ recommend the same amount, with the added stipulation that this is spread over at least five sessions. Previous research suggests both insufficient LTPA $^{9)}$ and excess dietary energy intake ${ }^{10)}$ are associated with increased risk of overweight and obesity. However, the relative importance of insufficient LTPA vs. excess dietary intake, remains inconclusive $^{11-13)}$.

While it is important to recognise the myriad of causal factors and the environmental context that contribute to overweight and obesity ${ }^{14)}$, researchers can still contribute to improved understanding of this phenomenon through the consideration of specific settings. As paid employment commonly occupies a significant proportion of time over the lifespan, it is important to understand how work factors may impact on health and wellbeing, and in turn how workplaces may promote and sustain good health ${ }^{15-17)}$. In this endeavour, the potential associations between psychosocial work factors, particularly work stress, and health outcomes have attracted significant research interest over the past $35 \mathrm{yr}^{18-21)}$.

There are many ways to conceptualise psychosocial work stress ${ }^{22}$, however the Job Demand-Control (JDC) model $^{23)}$, or its extension the Job Demand-ControlSupport (JDCS) model ${ }^{24)}$, is the most widely tested model. 'Job demands' describe the psychological effort related to workload, organisational constraints on task completion, and conflicting demands ${ }^{25}$ ). 'Job control' comprises two subscales: 'skill discretion' and 'decision authority'. Skill discretion refers to the level of skill and creativity required on the job and the flexibility an employee has in deciding what skills to use. Decision authority refers to the organisationally mediated potential for employees to make decisions about their work, or simply the type and quantity of decisions entailed in their work ${ }^{25}{ }^{26}$. The JDC model proposes that work stress can result due to a discrepancy between job demands and job control—generally when demands are too high and control is too low. The addition of 'social support' (two subscales: 'coworker support' and 'supervisor support') provides a third broad dimension to the model ${ }^{16,24)}$. Support refers to levels of helpful social interaction available on the job, received from coworkers and/or supervisors ${ }^{16)}$. Higher levels of social support are proposed to work in a similar way to higher levels of job control to mitigate the effects of high job demands.

Despite the prominence the JDC(S) model, studies vary considerably in their treatment and analysis of the model components. Most researchers combine 'skill discretion' and 'decision authority', and 'coworker support' and 'supervisor support', into the respective 'job control' and 'social support' composites as a preliminary step. Some then elect to consider the broad model constructs (i.e., demands, control, support) independently, while many others use a variety of approaches to calculate a global measure of 'job strain', or construct four categorical job strain groups (i.e., low strain, passive, active, and high strain) ${ }^{27)}$. Mixed findings are common in this field and may be a reflection of these operational inconsistencies ${ }^{28-31)}$. While the homonymous 'job strain' conceptualisations are traditionally the most prevalent operationalisations of the JDC(S) model, there is increasing consideration of the value in assessing the individual JDCS constructs separately. There may be additional value still in the consideration of the subscales of the two divisible constructs: job control (i.e., skill discretion and decision authority) and social support (i.e., coworker and supervisor support) ${ }^{32-35)}$. It has been speculated that in many modern work environments, higher skill discretion may be more beneficial for employee health, while higher decision authority (e.g., too many decisions) may be more detrimental ${ }^{36}$. In a previous study of the present sample, sex and age adjusted analyses suggested higher levels of skill discretion were associated with reduced measures of obesity (i.e., smaller BMI and waist circumference), while higher levels of decision authority were associated with increased measures of obesity (i.e., larger waist circumference ${ }^{32)}$. These findings suggest considering the JDCS model at the subscale level may be worthwhile and improve understanding by revealing more specific mechanisms.

Previous studies considering energy balance-related behaviours and the JDCS model at the subscale level have typically only provided bivariate associations between the two job control subscales (skill discretion and decision authority) and LTPA. Joensuu et al. ${ }^{35)}$ suggested more regular LTPA was reported by employees with higher 
levels of skill discretion, while no significant differences in LTPA were seen in relation to levels of decision authority. Conversely, Joensuu et al. ${ }^{37)}$ suggested lower levels of LTPA were reported by employees with higher levels of decision authority, but also for those reporting higher levels of skill discretion. With respect to these incongruous findings, it is important to note that LTPA was not the primary outcome of these studies and the relevant analyses did not control or adjust for the effects of sex or age. This is an important limitation since the subjective experiences of work may vary by sex, or men and women may differ systematically in the types of jobs they occupy and the associated psychosocial working conditions ${ }^{38,39)}$. Furthermore, increasing age is often associated with reduced physical activity, as well as changes in diet and increased weight ${ }^{40,41)}$. Nutritional requirements and corresponding recommendations also differ by sex and age; on average men are larger and generally require greater dietary energy intake to maintain homeostasis, while energy requirements generally reduce as age increases ${ }^{42)}$. One previous study did consider the individual associations of coworker and supervisor support with LTPA, finding no association in analyses that controlled for sex, age, and sociodemographic variables ${ }^{43)}$.

Previous research investigating the potential associations between psychosocial work factors and diet is scarce, and there is particularly little on dietary energy intake. One study, which controlled for age and stratified by sex, indicated job strain (ratio of job demands to control) was positively associated with daily intake of dietary fat in men only (i.e., higher job strain, higher dietary fat intake), while social support (composite of coworker and supervisor support) was positively associated with average daily energy intake from diet $(\mathrm{kcal} / \mathrm{d})$ for both men and women (i.e., higher support, higher dietary energy intake ${ }^{44)}$. The latter may be surprising since higher levels of stress are generally thought to increase dietary intake ${ }^{45}$, while higher levels of support are generally thought to alleviate work stress.

Our review of the literature has identified an exigent need for more research in relation to work stress and diet. In particular, studies that include measurement of total dietary energy intake are especially useful and compatible with the perspective of the positive energy balance hypothesis ${ }^{46)}$. Furthermore, the additional inclusion of a credentialed operationalisation of LTPA allows for exploration of potential associations between psychosocial work factors and both energy intake and expenditure-related behaviours $^{32)}$. It is important to note that such studies should also employ statistical methods to control for sex and age in their analyses. The aim of this study was to use an approach that adheres to these recommendations, and to investigate the possibility that subscales of the JDCS model may hold unique relationships with LTPA and/or dietary energy intake $(\mathrm{kJ} / \mathrm{d})$.

\section{Method}

\section{Sample and procedure}

The present study used a cross-sectional design drawing a sub-sample from the North West Adelaide Health Study (NWAHS). Demographic and LTPA data were collected using a computer-assisted telephone interview (CATI) at stage 3 of the NWAHS, conducted between June 2008 and August 2010. Dietary data were collected using a selfreport food frequency questionnaire mailed to participants during the same timeframe. Workplace and employmentrelated data were collected during a follow-up CATI, conducted between October and November 2011. The mean time between the two data collection phases was $2.32 \mathrm{yr}$ $(S D=0.54)$. To account for this discrepancy, the current study only included participants who reported being with their current workplace for at least $4 \mathrm{yr}$. Many participants reported considerably longer service than this minimum; the mean time with current workplace was $16.10 \mathrm{yr}(\mathrm{min}=4$, $\max =46, S D=9.48$ ).

Sampling processes related to the NWAHS involved random selection from the Northern and Western suburbs of Adelaide, South Australia, using an electronic telephone directory as detailed previously ${ }^{47,48}$. Participants were provided with detailed information about the study and required to sign informed consent forms ${ }^{47)}$. The initial sample, from stage 1 of the NWAHS (1999-2003), comprised 4,056 adults, while the 2011 CATI was restricted to a subset of participants (initial eligible $n=1,715$; i.e., those not lost to follow-up in earlier stages, and born between 1946-1980 as per requirement of a separate study). The eligible sample was reduced as $302(17.6 \%)$ had not worked in the interim and $47(2.7 \%)$ were not contactable. From the final eligible sample of 1,366 , a total of $1,185(86.7 \%)$ interviews were completed. Of these, 433 met criteria for modelling LTPA, and 409 for modelling dietary intake, in the present study (i.e., same workplace for $4 \mathrm{yr}$, no missing or outlying data for items in the regression models).

\section{Ethics}

Data collection was approved by the Adelaide Health Service Human Research Ethics Committee (comprising 
The Queen Elizabeth Hospital, Lyell McEwin Hospital, and Modbury Hospital), previously known as Central Northern Adelaide Health Service Ethics of Human Research Committee and North Western Adelaide Health Service Ethics of Human Research Committee.

\section{Measures}

Leisure-time physical activity. The first computerassisted telephone interview (CATI) incorporated six items from the Active Australia questionnaire ${ }^{8)}$ to capture data on the type, intensity, frequency, and duration of LTPA over the past week. Questions enquired about low intensity (e.g., walking continuously for at least $10 \mathrm{~min}$ ), moderate intensity (e.g., lawn bowls, golf, gentle swimming), and vigorous physical activity (e.g., tennis, jogging, cycling, keep fit exercises) that caused a large increase in breathing or heart rate. Two standard Active Australia items relating to vigorous gardening and heavy yard work were excluded to maintain brevity of the telephone interview and to avoid potential confusion with occupational physical activity. The Active Australia questionnaire has established reliability and validity in Australian populations ${ }^{49,50)}$.

In the present study, two definitions of LTPA were calculated - both comprise a three-level categorical variable that classifies participants into one of three groups: 'no activity', 'activity but not sufficient', or 'sufficient activity'. The frequency of activities was multiplied by the average time per session; with vigorous activity time multiplied by two, to account for the greater intensity of vigorous physical activity ${ }^{8)}$. For the first definition, 'sufficient activity' was defined as $\geq 150 \mathrm{~min}$ (or $\geq 75$ min vigorous intensity, or equivalent combination) per week of LTPA. The first definition is consistent with levels of physical activity for adults recommended by the World Health Organization ${ }^{7}$. The second definition is similar in that 'sufficient activity' is indicated by the same amount of physical activity per week, but it is also more stringent in that it specifies that this must occur over at least five sessions per week. The second definition is consistent with the National Physical Activity Guidelines for Australian adults ${ }^{8)}$. Distribution between LTPA groups for each definition is provided in Table 1.

Daily energy intake (kJ/d) from diet. A self-completed food frequency questionnaire, the Dietary Questionnaire for Epidemiological Studies (DQES v3.1), was mailed to participants to collect data on habitual diet relating to the previous 12 months. Returned forms were forwarded to Cancer Council Victoria for processing and analyses using the Australian Nutrient Data Table (NUTTAB 95) ${ }^{51)}$. The dietary questionnaire comprised 167-items, with most items describing a specific food for which participants rated their consumption using a 10-point frequency scale ranging from never to 3 or more times per day. Portion sizes were accounted for using four questions to calculate a unique portion size factor, which is used to scale up or down portion sizes for different foods, based on whether a person on average indicates median size serves (not scaled), more than the median (scaled up), or less than the median (scaled down $)^{52}$. Tea and coffee consumption were each reported using a 9-point frequency scale ranging from never or less than once per month to $6+$ cups per day. Diet and regular soft-drink consumption were each reported using a 12-point frequency scale ranging from none to $10+$ glasses per day. Consumption of alcoholic beverages (beer, wine, and spirits) were each reported using a respective portion estimate and an 8-point frequency scale ranging from never to every day.

The DQES was developed specifically for measuring dietary intake in Australian adults ${ }^{52)}$, and earlier versions have demonstrated validity ${ }^{53,54)}$, despite limitations characteristic of all food frequency questionnaires ${ }^{55)}$. For the present study, the dietary variable of interest is the estimated daily energy intake from diet, expressed as total kilojoules per day $(\mathrm{kJ} / \mathrm{d})$, including energy from fibre, alcoholic and non-alcoholic beverages. Distribution between sex-specific tertiles of $\mathrm{kJ} / \mathrm{d}$ are provided in Table 1, while properties of the continuous $\mathrm{kJ} / \mathrm{d}$ variable are provided in Table 2.

Psychosocial work factors. A follow-up CATI included items from the Job Content Questionnaire (JCQ) ${ }^{25)}$ used to calculate work-related psychological demands, skill discretion, decision authority, coworker support and supervisor support. The JCQ is the recommended and most commonly used instrument for measuring the JDCS dimensions ${ }^{25,27)}$, with established reliability and validity $^{25,26)}$. The present study utilised a 20 -item version and each item was accompanied with a 4-point response scale (e.g., 1=strongly disagree, 4=strongly agree). In order to build indicators for each dimension of the JDCS model, a sum of the weighted item scores was calculated as per instructions provided in the JCQ user guide ${ }^{56)}$. Psychometric properties of the resulting JDCS subscales used in analyses, including internal reliability estimates, are provided in Table 2.

Other work factors. Work hours were recorded as the average number of hours worked per week in main job over the past month. Employees were classified by job title as either blue or white-collar using the Australian 
Table 1. Summary of categorical variables

\begin{tabular}{|c|c|c|c|c|}
\hline Variable & $\begin{array}{l}\text { Whole sample (\%) } \\
\qquad \mathrm{N}=433\end{array}$ & $\begin{array}{c}\text { Male }(\%) \\
n=213\end{array}$ & $\begin{array}{c}\text { Female }(\%) \\
\mathrm{n}=220\end{array}$ & $\begin{array}{l}\text { Sex differences } \\
\chi^{2}(p)\end{array}$ \\
\hline \multicolumn{5}{|l|}{ Daily energy intake $(\mathrm{kJ} / \mathrm{d})\left[\right.$ Tertiles $\left.^{\mathrm{a}}\right]$} \\
\hline Low $[T 1$ : Men $\leq 8,097$, Women $\leq 7,080]$ & $136(33.3 \%)$ & $68(33.2 \%)$ & $68(33.3 \%)$ & \\
\hline Middle [T2: Men 8,098-9,901, Women 7,081-8,618] & $137(33.5 \%)$ & $69(33.7 \%)$ & $68(33.3 \%)$ & \\
\hline High $[\mathrm{T} 3$ : Men $\geq 9,902$, Women $\geq 8,619]$ & $136(33.3 \%)$ & $68(33.2 \%)$ & $68(33.3 \%)$ & \\
\hline Missing & 24 & 8 & 16 & - \\
\hline \multicolumn{5}{|l|}{ Leisure-time physical activity (Definition 1) } \\
\hline No activity & $70(16.2 \%)$ & $35(16.4 \%)$ & $35(15.9 \%)$ & \\
\hline Activity but not sufficient & $144(33.3 \%)$ & $69(32.4 \%)$ & $75(34.1 \%)$ & \\
\hline Sufficient activity $[\geq 150 \mathrm{~min} / \mathrm{wk}]$ & $219(50.6 \%)$ & $109(51.2 \%)$ & $110(50.0 \%)$ & 0.932 \\
\hline \multicolumn{5}{|l|}{ Leisure-time physical activity (Definition 2) } \\
\hline No activity & $70(16.2 \%)$ & $35(16.4 \%)$ & $35(15.9 \%)$ & \\
\hline Activity but not sufficient & $187(43.2 \%)$ & $97(45.5 \%)$ & $90(40.9 \%)$ & \\
\hline Sufficient activity [ $\geq 150 \mathrm{~min} / \mathrm{wk}, \geq 5$ sessions] & $176(40.6 \%)$ & $81(38.0 \%)$ & $95(43.2 \%)$ & 0.532 \\
\hline \multicolumn{5}{|l|}{ Psychological demands [Tertiles $\left.{ }^{\mathrm{b}}\right]$} \\
\hline Low $[\mathrm{T} 1: \leq 29]$ & $133(30.7 \%)$ & $69(32.4 \%)$ & $64(29.1 \%)$ & \\
\hline Middle [T2: 30-33] & $124(28.6 \%)$ & $77(36.2 \%)$ & $47(21.4 \%)$ & \\
\hline High $[\mathrm{T} 3: \geq 34]$ & $176(40.6 \%)$ & $67(31.5 \%)$ & $109(49.5 \%)$ & $<0.001 * * *$ \\
\hline \multicolumn{5}{|l|}{ Skill discretion $\left[\right.$ Tertiles $\left.^{\mathrm{b}}\right]$} \\
\hline Low $[\mathrm{T} 1: \leq 32]$ & $135(31.2 \%)$ & $69(32.4 \%)$ & $66(30.0 \%)$ & \\
\hline Middle [T2: 33-36] & $149(34.4 \%)$ & $82(38.5 \%)$ & $67(30.5 \%)$ & \\
\hline $\operatorname{High}[\mathrm{T} 3: \geq 37]$ & $149(34.4 \%)$ & $62(29.1 \%)$ & $87(39.5 \%)$ & 0.059 \\
\hline \multicolumn{5}{|l|}{ Decision authority [Tertiles $\left.{ }^{\mathrm{b}}\right]$} \\
\hline Low $[\mathrm{T} 1: \leq 32]$ & $141(32.6 \%)$ & $60(28.2 \%)$ & $81(36.8 \%)$ & \\
\hline Middle [T2: 33-36] & $181(41.8 \%)$ & $96(45.1 \%)$ & $85(38.6 \%)$ & \\
\hline High $[\mathrm{T} 3: \geq 37]$ & $111(25.6 \%)$ & $57(26.8 \%)$ & $54(24.5 \%)$ & 0.152 \\
\hline \multicolumn{5}{|l|}{ Coworker support [Median $\left.{ }^{\mathrm{b}}\right]$} \\
\hline Low $[\leq 9]$ & $288(66.5 \%)$ & $148(69.5 \%)$ & $140(63.6 \%)$ & \\
\hline $\operatorname{High}[\geq 10]$ & $145(33.5 \%)$ & $65(30.5 \%)$ & $80(36.4 \%)$ & $0.235^{\mathrm{f}}$ \\
\hline \multicolumn{5}{|l|}{ Supervisor support [Median $\left.{ }^{\mathrm{b}}\right]$} \\
\hline Low $[\leq 9]$ & $301(69.5 \%)$ & $152(71.4 \%)$ & $149(67.7 \%)$ & \\
\hline $\operatorname{High}[\geq 10]$ & $132(30.5 \%)$ & $61(28.6 \%)$ & $71(32.3 \%)$ & $0.473^{\mathrm{f}}$ \\
\hline \multicolumn{5}{|l|}{ Job nature (ANZSCO ${ }^{c}$ code) } \\
\hline Blue-collar & $89(20.6 \%)$ & $66(31.0 \%)$ & $23(10.5 \%)$ & \\
\hline White-collar & $344(79.4 \%)$ & $147(69.0 \%)$ & $197(89.5 \%)$ & $<0.001^{\mathrm{f} * * *}$ \\
\hline \multicolumn{5}{|l|}{ Household income ${ }^{\mathrm{d}}\left[\right.$ Median $\left.^{\mathrm{b}}\right]$} \\
\hline Up to $\$ 80,000$ & $206(47.6 \%)$ & $99(46.5 \%)$ & $107(48.6 \%)$ & \\
\hline$\$ 80,001+$ & $227(52.4 \%)$ & $114(53.5 \%)$ & $113(51.4 \%)$ & $0.724^{\mathrm{f}}$ \\
\hline \multicolumn{5}{|l|}{ Employment type } \\
\hline Part time & $117(27.0 \%)$ & $12(5.6 \%)$ & $105(47.7 \%)$ & \\
\hline Full time & $316(73.0 \%)$ & $201(94.4 \%)$ & $115(52.3 \%)$ & $<0.001^{\mathrm{f} * * *}$ \\
\hline \multicolumn{5}{|l|}{ Education } \\
\hline Did not complete high school & $94(21.7 \%)$ & $39(18.3 \%)$ & $55(25.0 \%)$ & \\
\hline Completed high school & $57(13.2 \%)$ & $21(9.9 \%)$ & $36(16.4 \%)$ & \\
\hline TAFEe/Apprenticeship & $38(8.8 \%)$ & $23(10.8 \%)$ & $15(6.8 \%)$ & \\
\hline Trade certificate or diploma & $119(27.5 \%)$ & $77(36.2 \%)$ & $42(19.1 \%)$ & \\
\hline Bachelor degree or higher & $125(28.9 \%)$ & $53(24.9 \%)$ & $72(32.7 \%)$ & $<0.001 * * *$ \\
\hline
\end{tabular}

Valid column\% reported. ${ }^{\text {a }}$ Sex-specific tertiles, ${ }^{\mathrm{b}}$ Sample tertiles or median split as specified, ${ }^{\mathrm{c}}$ Australian and New Zealand Standard Classification of Occupations, First Edition, Revision 1, ${ }^{\mathrm{d}}$ Amount in Australian dollars, ${ }^{\mathrm{e}}$ Technical and Further Education (vocational education and training), ${ }^{\mathrm{f}}$ Yates' correction for $2 \times 2$ table. ${ }^{*} p<0.05,{ }^{* *} p<0.01,{ }^{* * *} p \leq 0.001$. 


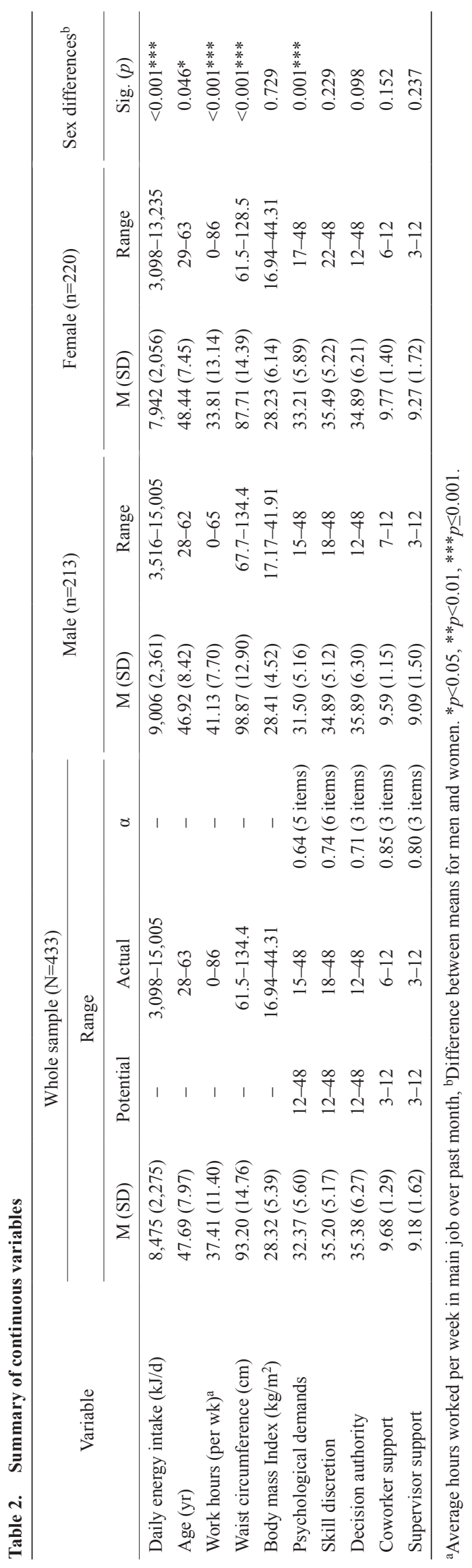

and New Zealand Standard Classification of Occupations $(\mathrm{ANZSCO})^{57)}$.

Anthropometric measurements. Participant height, weight, and waist circumference were measured by clinic staff using standardised protocols and were recorded as continuous variables (Table 2). Waist circumference and BMI (weight $/$ height $^{2}$ ) were the variables of interest in a previous study ${ }^{32)}$, and are provided here to illustrate the representativeness of the sample.

\section{Analyses}

Continuous daily energy intake $(\mathrm{kJ} / \mathrm{d})$ was divided into sex-specific tertiles, owing to the generally higher intake requirements and subsequent differences in recommended daily intake for men compared to women ${ }^{42}$. Continuous JDCS variables were divided into sample-specific tertiles (psychological demands, skill discretion, and decision authority) and median splits (coworker support and supervisor support) using the most even sample-specific cut points available in the distribution for the respective variables. Median splits were used instead of tertiles for the coworker and supervisor support variables because these scales have a narrower range and reduced variance due to the fewer number of items for these constructs. Whole sample and sex-specific distributions of these categorical variables are provided in Table 1.

Univariate outliers for daily energy intake $(\mathrm{kJ} / \mathrm{d})$ were screened using separate box-and-whisker plots for men and women, with interquartile range (IQR) calculated using Tukey's Hinges (Q3-Q1). For men, upper outliers $(\geq Q$ 3 $+[1.5 \times \mathrm{IQR}])$ were determined as values $\geq 15,170 \mathrm{~kJ} / \mathrm{d}$, and lower outliers $(\leq \mathrm{Q} 1-[1.5 \times \mathrm{IQR})$ were determined as values $\leq 3,034 \mathrm{~kJ} / \mathrm{d}$. For women, upper outliers $(\geq \mathrm{Q} 3$ $+[1.5 \times \mathrm{IQR}])$ were determined as values $\geq 13,411 \mathrm{~kJ} / \mathrm{d}$, and lower outliers $(\leq \mathrm{Q} 1-[1.5 \times \mathrm{IQR})$ were determined as $\leq 2,680 \mathrm{~kJ} / \mathrm{d}$. Based on these definitions, six men and nine women were classified as upper outliers, while one woman was classified as a lower outlier. A linear regression using the continuous measure of energy intake $(\mathrm{kJ} / \mathrm{d})$ was conducted for the purposes of identifying multivariate outliers; this revealed one additional male outlier case with standardised residuals $\geq 3$. All cases identified as outliers were excluded from all analyses. Cases with missing data for the items in the respective regression models were also excluded. Data on participant educational attainment is presented in Table 1, however household income, an alternative measure of socioeconomic status, was used as a control variable in regression analyses as it was found to account for greater variance in our sample. 
Separate multinomial logistic regression analyses were conducted for each model, providing odds ratios (OR) and $95 \%$ confidence intervals $(95 \% \mathrm{CI})$, to determine associations between subscales of the JDCS model and the two definitions of LTPA (Tables 3 and 4), as well as daily energy intake $(\mathrm{kJ} / \mathrm{d}$, Table 5). In all analyses, Model 1 comprised crude analyses (i.e., JDCS constructs only, no control variables), Model 2 controlled for sex and age, and Model 3 included additional control variables: household income, working hours and job nature (blue vs. white-collar). Due to our moderate sample size, to preserve statistical power in our main analyses (Tables 3-5), we controlled for sex rather than present results for men and women separately. Supplementary analyses stratified by sex are reported in Appendix 1. All analyses were conducted in IBM SPSS Statistics for Windows (Version 24.0).

\section{Results}

Participant occupational and socioeconomic characteristics

A summary of descriptive categorical and continuous variables are provided in Tables 1 and 2 respectively. The sample comprised 433 ( $n=220,50.8 \%$ female), mostly middle-aged (mean age $=47.69 \mathrm{yr}$ ) employees. The majority of participants (both men and women) were overweight or obese $\left(\right.$ mean $\left.\mathrm{BMI}=28.32 \mathrm{~kg} / \mathrm{m}^{2}\right)$. As detailed in Table 1, men (31.0\%) were more likely to hold blue-collar positions compared to women (10.5\%); men also reported working full-time (94.4\%) more often than women $(52.3 \%)$. As such, men reported greater working hours per week on average (mean=41.13 h) compared to women (mean=33.81 h), as detailed in Table 2 . Approximately half of the participants, both men $(53.5 \%)$ and women (51.4\%), reported household income above \$80,001 (Australian dollars), while the remaining half reported household income up to $\$ 80,000$. There were sex differences in the highest level of education attained: for men the most common qualification was a trade certificate or diploma $(36.2 \%)$, while for women the most common qualification was a bachelor's degree or higher $(32.7 \%)$. As detailed in Table 1, scores for the JDCS constructs were generally comparable for men and women, with the exception of psychological demands where women (49.5\%) were more likely to report scores in the top tertile (i.e., high demands) compared to men $(31.5 \%)$.

\section{Leisure-time physical activity}

Levels of LTPA were comparable between men and women for both LTPA definition 1 ('sufficient activity' defined as $\geq 150$ min per wk of LTPA) and definition 2 ('sufficient activity' defined as $\geq 150$ min per wk, over $\geq 5$ sessions) (Table 1). In the regression analyses, the 'low' tertile was used as the reference group for the respective JDCS constructs, while 'no activity' was used as the LTPA reference group for both LTPA definition 1 (Table 3) and definition 2 (Table 4). The pattern of associations with regression variables was generally consistent for both LTPA definitions and across the three models presented. Across all analyses (Models 1-3; Tables 3 and 4), skill discretion was the only JDCS subscale associated with either definition of LTPA - with generally higher ORs for 'activity but not sufficient' observed for LTPA definition 1 (Table 3), and generally higher ORs for 'sufficient activity' observed for the more stringent LTPA definition 2 (Table 4).

In crude analyses (Model 1; Tables 3 and 4), a positive association was observed between skill discretion and LTPA. Employees reporting scores in the highest tertile of skill discretion (compared to the lowest tertile) were more likely to be in the 'sufficient activity' group (compared to 'no activity' group) for LTPA definition 1 ( $\mathrm{OR}=2.29$; 95\% $\mathrm{CI}=1.07-4.87)$, and LTPA definition $2(\mathrm{OR}=2.63 ; 95 \%$ $\mathrm{CI}=1.21-5.71)$. Employees reporting scores in the highest tertile of skill discretion (compared to the lowest tertile) were also more likely to be in the 'activity but not sufficient' group (compared to 'no activity' group) for LTPA definition $1(\mathrm{OR}=3.93$; 95\% $\mathrm{CI}=1.72-8.97)$, and definition 2 ( $\mathrm{OR}=2.95 ; 95 \% \mathrm{CI}=1.35-6.44)$. Employees reporting scores in the middle tertile of skill discretion (compared to the lowest tertile) also had a greater likelihood of being in the 'activity but not sufficient' group (compared to 'no activity' group) for LTPA definition 1 ( $\mathrm{OR}=2.99$; $95 \% \mathrm{CI}=1.44-6.20)$, and definition $2(\mathrm{OR}=2.41 ; 95 \%$ $\mathrm{CI}=1.21-4.79)$.

In sex and age adjusted analyses (Model 2; Tables 3 and 4), sex did not appear to be directly associated with either LTPA definition, while a negative association was observed between age and LTPA. Employees with higher age (yr) had a reduced likelihood of being in the 'sufficient activity' group (compared to 'no activity' group) for LTPA definition 1 ( $\mathrm{OR}=0.96$; 95\% CI=0.92-0.99), and definition $2(\mathrm{OR}=0.96$; $95 \% \mathrm{CI}=0.92-0.99)$. Employees with higher age (yr) also had a reduced likelihood of being in the 'activity but not sufficient' group (compared to 'no activity' group) for LTPA definition 1 ( $\mathrm{OR}=0.95$; $95 \%$ $\mathrm{CI}=0.91-0.99)$, and LTPA definition $2(\mathrm{OR}=0.95 ; 95 \%$ $\mathrm{CI}=0.92-0.99)$. The addition of sex and age in Model 2, amplified the ORs for the associations between skill discretion and LTPA observed in crude analyses (Model 2 in 


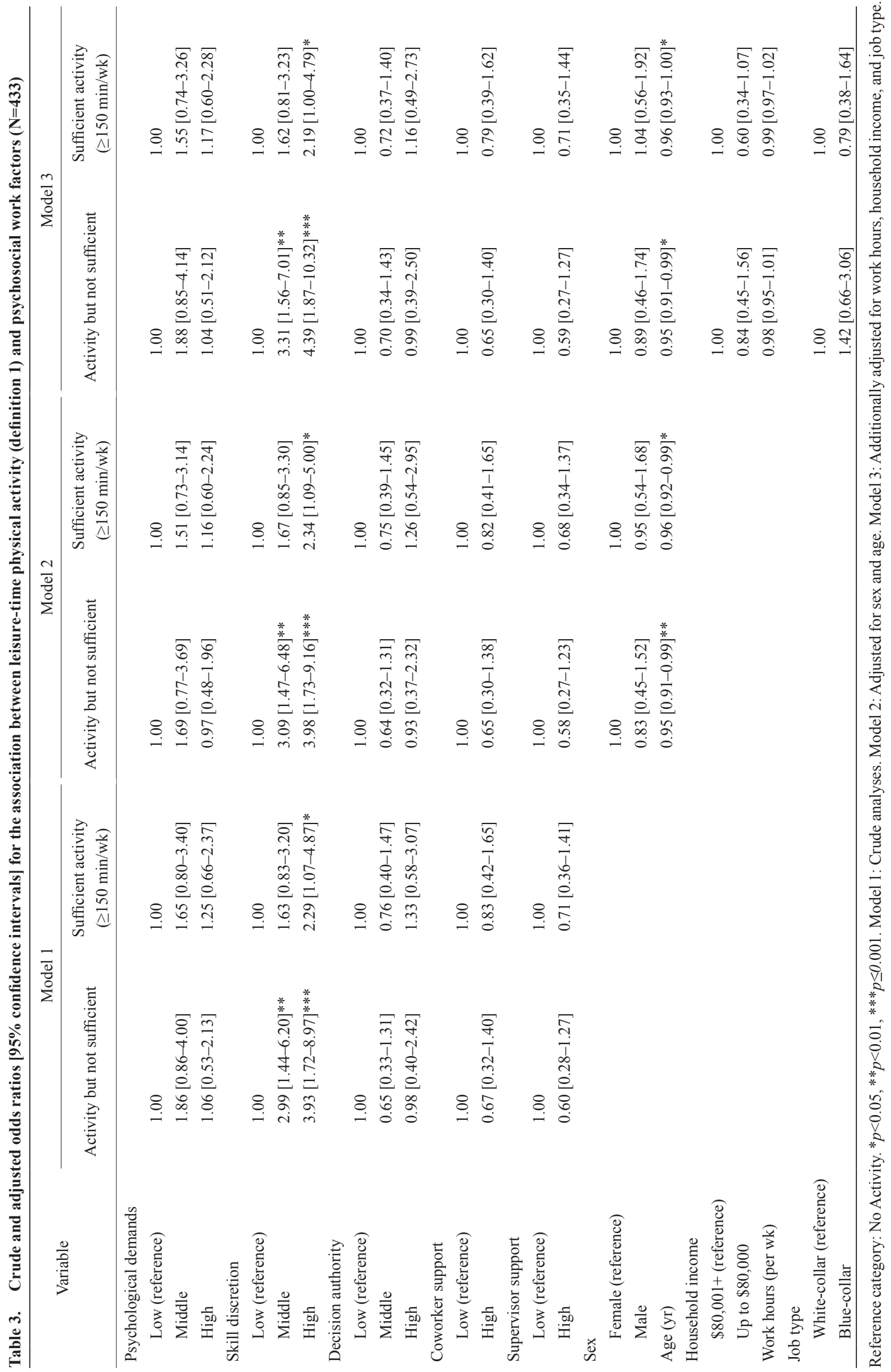




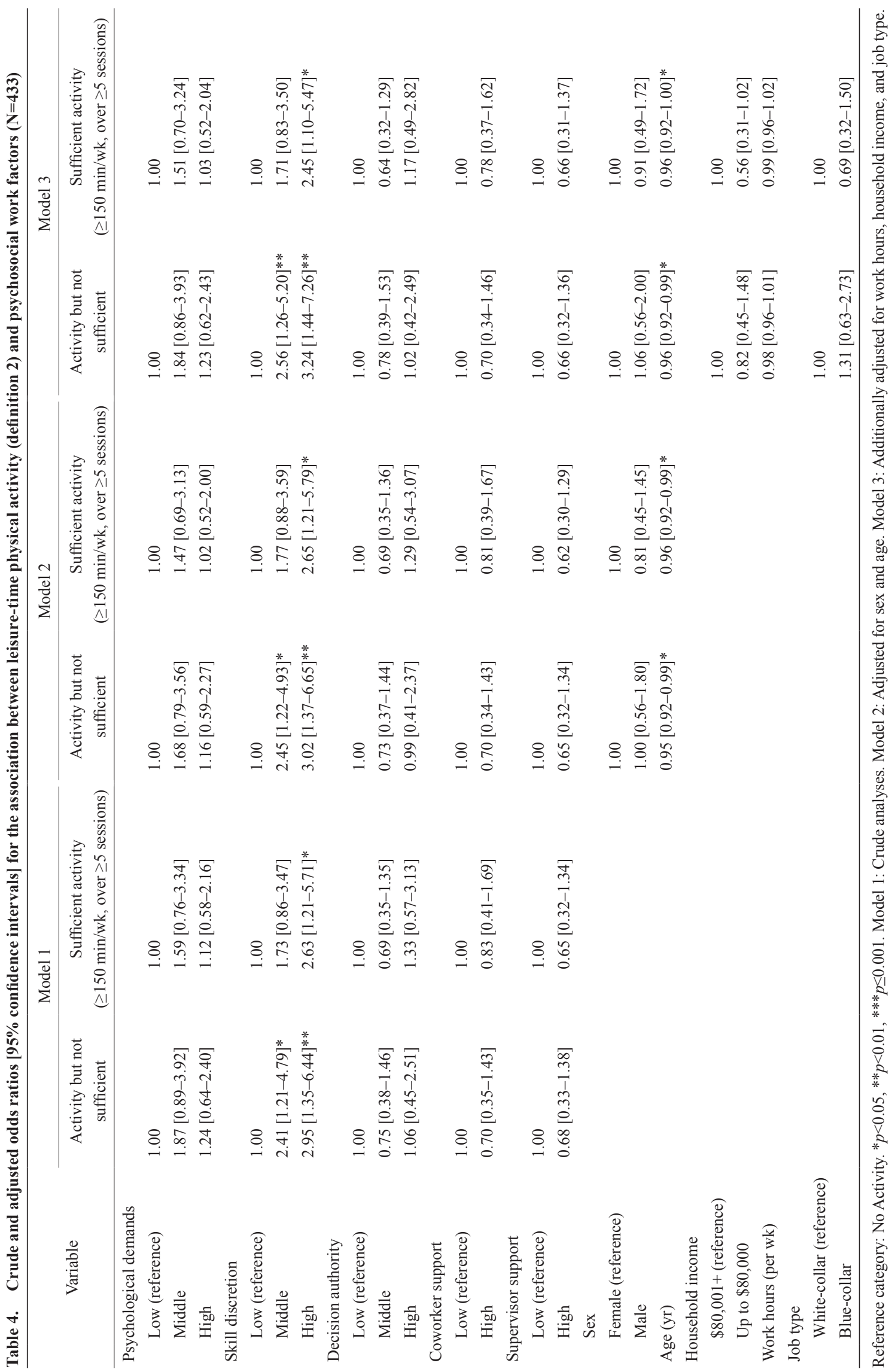


Table 5. Crude and adjusted odds ratios [ $95 \%$ confidence intervals] for the association between sex-specific tertiles of daily energy intake $(\mathrm{kJ} / \mathrm{d})$ from diet and psychosocial work factors $(\mathrm{N}=409)$

\begin{tabular}{|c|c|c|c|c|c|c|}
\hline \multirow[b]{2}{*}{ Variable } & \multicolumn{2}{|c|}{ Model 1} & \multicolumn{2}{|c|}{ Model 2} & \multicolumn{2}{|c|}{ Model 3} \\
\hline & $\begin{array}{l}\text { Middle } \mathrm{kJ} / \mathrm{d} \\
\text { (Tertile 2) }\end{array}$ & $\begin{array}{l}\text { High kJ/d } \\
\text { (Tertile 3) }\end{array}$ & $\begin{array}{l}\text { Middle kJ/d } \\
\text { (Tertile 2) }\end{array}$ & $\begin{array}{l}\text { High kJ/d } \\
\text { (Tertile 3) }\end{array}$ & $\begin{array}{l}\text { Middle kJ/d } \\
\text { (Tertile 2) }\end{array}$ & $\begin{array}{l}\text { High kJ/d } \\
\text { (Tertile 3) }\end{array}$ \\
\hline \multicolumn{7}{|l|}{ Psychological demands } \\
\hline Low (reference) & 1.00 & 1.00 & 1.00 & 1.00 & 1.00 & 1.00 \\
\hline Middle & $1.21[0.65-2.24]$ & $0.93[0.49-1.78]$ & $1.17[0.63-2.20]$ & $0.95[0.49-1.82]$ & $1.13[0.60-2.13]$ & $0.95[0.49-1.85]$ \\
\hline High & $1.10[0.60-2.00]$ & $1.17[0.64-2.13]$ & $1.10[0.60-2.00]$ & $1.21[0.66-2.21]$ & $1.08[0.59-2.00]$ & $1.24[0.67-2.31]$ \\
\hline \multicolumn{7}{|l|}{ Skill discretion } \\
\hline Low (reference) & 1.00 & 1.00 & 1.00 & 1.00 & 1.00 & 1.00 \\
\hline Middle & $0.98[0.53-1.79]$ & $1.78[0.95-3.32]$ & $0.97[0.53-1.78]$ & $1.76[0.94-3.29]$ & $0.98[0.53-1.83]$ & $1.95[1.03-3.71]^{*}$ \\
\hline High & $1.02[0.53-1.95]$ & $1.40[0.70-2.79]$ & $1.02[0.53-1.97]$ & $1.41[0.71-2.82]$ & $0.97[0.49-1.90]$ & $1.54[0.75-3.15]$ \\
\hline \multicolumn{7}{|l|}{ Decision authority } \\
\hline Low (reference) & 1.00 & 1.00 & 1.00 & 1.00 & 1.00 & 1.00 \\
\hline Middle & $0.74[0.41-1.34]$ & $0.71[0.40-1.28]$ & $0.73[0.41-1.33]$ & $0.71[0.39-1.27]$ & $0.75[0.41-1.37]$ & $0.80[0.44-1.46]$ \\
\hline High & $0.73[0.36-1.47]$ & $0.35[0.16-0.73]^{* *}$ & $0.71[0.35-1.44]$ & $0.34[0.16-0.73]^{* *}$ & $0.76[0.37-1.56]$ & $0.43[0.20-0.93]^{*}$ \\
\hline \multicolumn{7}{|l|}{ Coworker support } \\
\hline Low (reference) & 1.00 & 1.00 & 1.00 & 1.00 & 1.00 & 1.00 \\
\hline High & $1.58[0.84-2.98]$ & $2.25[1.19-4.25]^{*}$ & $1.58[0.84-2.98]$ & $2.30[1.21-4.34]^{*}$ & $1.51[0.79-2.87]$ & $2.20[1.15-4.23]^{*}$ \\
\hline \multicolumn{7}{|l|}{ Supervisor support } \\
\hline Low (reference) & 1.00 & 1.00 & 1.00 & 1.00 & 1.00 & 1.00 \\
\hline High & $1.48[0.78-2.79]$ & $1.73[0.91-3.27]$ & $1.48[0.79-2.80]$ & $1.74[0.91-3.29]$ & $1.48[0.78-2.79]$ & $1.76[0.92-3.36]$ \\
\hline \multicolumn{7}{|l|}{ Sex } \\
\hline Female (reference) & & & 1.00 & 1.00 & 1.00 & 1.00 \\
\hline Male & & & $1.06[0.65-1.75]$ & $1.18[0.71-1.95]$ & $1.25[0.73-2.14]$ & $1.47[0.83-2.59]$ \\
\hline Age (yr) & & & $0.99[0.96-1.02]$ & $1.01[0.98-1.04]$ & $0.99[0.96-1.02]$ & $1.01[0.97-1.04]$ \\
\hline \multicolumn{7}{|l|}{ Household income } \\
\hline$\$ 80,001+($ reference $)$ & & & & & 1.00 & 1.00 \\
\hline Up to $\$ 80,000$ & & & & & $1.52[0.91-2.54]$ & $2.17[1.28-3.67]^{* *}$ \\
\hline Work hours (per wk) & & & & & $0.99[0.97-1.02]$ & $0.98[0.95-1.00]$ \\
\hline \multicolumn{7}{|l|}{ Job type } \\
\hline White-collar (reference) & & & & & 1.00 & 1.00 \\
\hline Blue-collar & & & & & $0.56[0.29-1.09]$ & $0.85[0.44-1.62]$ \\
\hline
\end{tabular}

Reference category: Low kJ/day (Tertile 1). ${ }^{*} p<0.05,{ }^{* *} p<0.01,{ }^{* * *} p \leq 0.001$. Model 1: Crude analyses. Model 2: Adjusted for sex and age. Model 3: Additionally adjusted for work hours, household income, and job type.

Tables 3 and 4, for respective ORs and 95\% CIs).

In the final, full adjusted analyses (Model 3; Tables 3 and 4), household income (median split: $<\$ 80,000$ vs. $\$ 80,001+$ ), work hours (hours per week), and job type (blue vs. white-collar) were included as additional control variables. None of these additional variables appeared to be associated with LTPA, however the associations previously noted in Models 1 and 2 (Tables 3 and 4) remained significant in this final model (Model 3, Tables 3 and 4 for respective ORs and 95\% CIs). The final models were statistically significant for both LTPA definition $1, \chi^{2}(26$, $N=433)=43.97, p=0.015$; and definition $2, \chi^{2}(26, N=433)$ $=40.99, p=0.031$. Pseudo $R^{2}$ indicators suggest the full adjusted models as a whole explained between 9.7\% (Cox and Snell $R^{2}$ ) and $11.1 \%$ (Nagelkerke $R^{2}$ ) of variance in LTPA status for definition 1, and between $9.0 \%$ (Cox and Snell $R^{2}$ ) and $10.4 \%$ (Nagelkerke $R^{2}$ ) of variance in LTPA status for definition 2 .

Additional analyses were conducted to explore the possibility of sex differences in the associations between the JDCS constructs and LTPA. Using sex-stratified multinomial logistic regression models, with the same structure as those presented in Model 3 for Tables 3 and 4 respectively, results indicate potentially divergent associations between the regression variables and LTPA for men $(n=213)$ and women $(n=220)$. Reported in full in Appendix 1, these 
stratified results are summarised in the Discussion.

\section{Daily energy intake $(\mathrm{kJ} / \mathrm{d})$ from diet}

Men reported higher daily energy intake on average compared to women (Table 2). The creation of sexspecific tertiles (low, middle, high $\mathrm{kJ} / \mathrm{d}$ ) facilitated unified analyses, whereby men and women were included in the same regression models (Table 5). Sex-specific cut-points used to evenly divide male and female participants into the sex-specific $\mathrm{kJ} / \mathrm{d}$ tertiles are provided in Table 1 . In the regression analyses, the 'low' tertile was used as the reference group for the respective JDCS constructs, while 'low $\mathrm{kJ} / \mathrm{d}$ ' was used as the energy intake reference group for all analyses in Table 5. Across all analyses (Models 1-3; Table 5) the most consistent associations, between daily energy intake $(\mathrm{kJ} / \mathrm{d})$ and the JDCS constructs, were observed with decision authority and coworker support.

In crude analyses (Model 1; Table 5), a negative association was observed between decision authority and daily energy intake $(\mathrm{kJ} / \mathrm{d})$ from diet. Employees reporting scores in the highest tertile of decision authority (compared to the lowest tertile) had a reduced likelihood ( $\mathrm{OR}=0.35 ; 95 \%$ $\mathrm{CI}=0.16-0.73$ ) of being in the 'high $\mathrm{kJ} / \mathrm{d}$ ' tertile (compared to 'low $\mathrm{kJ} / \mathrm{d}$ ' tertile). A positive association was observed between coworker support and daily energy intake $(\mathrm{kJ} /$ d) from diet. Employees reporting above median scores for coworker support were more likely $(\mathrm{OR}=2.25 ; 95 \%$ $\mathrm{CI}=1.19-4.25$ ) to be in the 'high $\mathrm{kJ} / \mathrm{d}$ ' tertile (compared to 'low $\mathrm{kJ} / \mathrm{d}$ ' tertile).

In sex and age adjusted analyses (Model 2; Table 5), considering that the $\mathrm{kJ} / \mathrm{d}$ tertiles were sex-specific, neither sex nor age appeared to be directly associated with daily energy intake $(\mathrm{kJ} / \mathrm{d})$ from diet. The addition of sex and age in Model 2, had minimal influence on the ORs for the associations between daily energy intake $(\mathrm{kJ} / \mathrm{d})$ from diet and decision authority, and coworker support (Model 2 in Table 5, for respective ORs and 95\% CIs). In the final, full adjusted analyses (Model 3; Table 5), household income (median split: $<\$ 80,000$ vs. $\$ 80,001+$ ), work hours (h per wk), and job type (blue vs. white-collar) were included as additional control variables. Only one of these additional variables - household income, appeared to be associated with daily energy intake $(\mathrm{kJ} / \mathrm{d})$ from diet, and the associations previously noted in Models 1 and 2 (Table 5) remained significant in this final model (Model 3, Table 5 for respective ORs and 95\% CIs). For household income, employees reporting less than the sample median household income (up \$80,000 Australian dollars), were more likely $(\mathrm{OR}=2.17 ; 95 \% \mathrm{CI}=1.28-3.67)$ to be in the 'high $\mathrm{kJ} /$ d' tertile (compared to 'low $\mathrm{kJ} / \mathrm{d}$ ' tertile). Model 3 (Table 5) also suggested a potentially curvilinear association between skill discretion and daily energy intake $(\mathrm{kJ} / \mathrm{d})$ from diet, whereby employees reporting scores in the middle tertile of skill discretion (compared to the lowest tertile) had a greater likelihood $(\mathrm{OR}=1.95 ; 95 \% \mathrm{CI}=1.03-3.71)$ of being in the 'high $\mathrm{kJ} / \mathrm{d}$ ' tertile (compared to 'low $\mathrm{kJ} / \mathrm{d}$ ' tertile). The final model for daily energy intake $(\mathrm{kJ} / \mathrm{d})$ from diet was statistically significant, $\chi^{2}(26, N=409)=44.92$, $p=0.012$. Pseudo $R^{2}$ indicators suggest the full adjusted model as a whole explained between $10.4 \%$ (Cox and Snell $R^{2}$ ) and $11.7 \%$ (Nagelkerke $R^{2}$ ) of variance in daily energy intake $(\mathrm{kJ} / \mathrm{d})$ from diet.

Additional analyses were conducted to explore the possibility of sex differences in the associations with daily energy intake $(\mathrm{kJ} / \mathrm{d})$ from diet. Using sex-stratified multinomial logistic regression models, with the same structure as those presented in Model 3 of Table 5, results indicate potentially divergent associations between the regression variables and daily energy intake $(\mathrm{kJ} / \mathrm{d})$ from diet, for men $(n=205)$ and women $(n=204)$. Reported in full in Appendix 1 , these stratified results are summarised in the Discussion.

\section{Discussion}

This study comprised a subscale level consideration of the JDCS model in relation to two proximal health behaviours, LTPA and dietary energy intake $(\mathrm{kJ} / \mathrm{d})$, which may mediate the potential association between psychosocial work factors and overweight and obesity. This study was the first of its kind to consider these energy balance-related behaviours, using analyses that did not reduce the JDCS subscales into composite or global scores, but which did control for the effects of sex and age, as well as relevant sociodemographic variables. Notably a number of JDCS subscales appear to hold individual associations with LTPA or dietary energy intake $(\mathrm{kJ} / \mathrm{d})$. The divergent nature of these associations, particularly for the two subscales of job control (skill discretion and decision authority), suggests that they would have been masked if a broader approach to analyses, such as using a global measure of job strain or the four job strain groups had been used instead. As such, these findings may help explain why previous research investigating the association between job strain and obesity has produced inconclusive finding $\mathrm{s}^{58,59)}$.

With regards to the two subscales of job control, the results of the present study suggest skill discretion is strongly associated with LTPA, while decision authority is not. The positive association between skill discretion 
and LTPA appears linear, whereby both middle and high levels of skill discretion (compared to low levels) were associated with increased likelihood of attaining 'activity but not sufficient' and 'sufficient activity'. Furthermore, these associations were amplified after controlling for the effects of sex and age, and persisted after controlling for additional sociodemographic variables of household income, work hours, and job type (blue vs. white-collar). This findings is consistent with a previous observation that skill discretion is negatively associated with measures of obesity (i.e., higher levels of skill discretion, smaller BMI and waist circumference) ${ }^{32}$. No other parts of the JDCS model appeared to be associated with LTPA. Additional sex-stratified analyses were conducted to explore potential sex differences, however in these analyses statistical power was reduced since stratifying by sex effectively halved the respective sample sizes. These analyses suggest that the associations between skill discretion and LTPA may be stronger for men as higher ORs were observed in malespecific analyses, and the associations were not significant for women in female-specific analyses. While the association between skill discretion and LTPA was not observed in female-specific analyses, this may due to a weaker association that requires a larger sample to be observed.

While skill discretion was strongly associated with LTPA - an important source of energy expenditure, it did not appear to be clearly associated with dietary energy intake $(\mathrm{kJ} / \mathrm{d})$. Instead, results of the present study suggest high levels of decision authority are strongly associated with dietary energy intake $(\mathrm{kJ} / \mathrm{d})$. In the negative association between daily energy intake and decision authority, high levels of decision authority (compared to low levels) were associated with reduced likelihood of being in the highest tertile of daily energy intake (compared to 'low $\mathrm{kJ} /$ day' tertile). Furthermore this association persisted after controlling for the effects of sex, age, household income, work hours, and job type (blue vs. white-collar). This finding is consistent with the traditional perspective that higher levels of decision authority may be beneficial for employee health, but at odds with emerging evidence that higher levels of decision authority (e.g., too many decisions) may be more likely detrimental in the modern work context ${ }^{36)}$. This finding is also surprising since a previous study, using the same sample as the present study, suggested decision authority was positively associated with indicators of obesity (i.e., higher levels of decision authority, higher waist circumference) ${ }^{32}$. There are two important factors to consider in the interpretation of this observation-firstly, the association between skill discretion and LTPA appears stronger than the association between decision authority and energy intake from diet - as such, higher levels of skill discretion may outweigh the influence of higher levels of decision authority. The second important consideration is the potential for measurement error for daily energy intake, discussed further in the limitations section.

The positive association between coworker support and dietary energy intake $(\mathrm{kJ} / \mathrm{d})$ was somewhat surprising, wherein high levels of coworker support (compared to low levels) were associated with increased likelihood of being in the highest tertile of daily energy intake (compared to 'low $\mathrm{kJ} / \mathrm{d}$ ' tertile). This association persisted after controlling for the effects of sex, age, household income, work hours, and job type (blue vs. white-collar). While inconsistent with the traditional perspective that higher levels of support are associated with reduced work stress and better health outcomes ${ }^{6-62)}$, a similar finding was reported by Kawakami et al. ${ }^{44)}$, who found a positive association between daily energy intake and the composite workplace support construct (i.e., combined coworker and supervisor support). Kawakami et al. ${ }^{44)}$ speculated that higher levels of social support may be associated with greater opportunities for employees to eat high-calorie foods together at social gatherings, such as morning teas, perhaps with cake or snacks in communal staff areas.

No other parts of the JDCS model appeared to be clearly associated with dietary intake. Additional sex-stratified analyses were conducted to explore potential sex differences. The only JDCS relevant association to persist in the sex-specific analyses was the positive association between coworker support and energy intake for male employees. However, the model fit for the male-specific analyses was not significant. While associations between energy intake and JDCS model components were generally not observed in sex-specific analyses, these analyses comprised reduced statistical power compared to the main analyses.

Observations in the present study validate the importance of controlling for the effects of sex and age in investigations of this nature. Increasing age was associated with a decreased likelihood of engaging in LTPA, for both LTPA definitions used. The negative association between age and LTPA suggests positive energy balance may increase with age, since age was not associated with a reduction in daily energy intake $(\mathrm{kJ} / \mathrm{d})$ in the present sample. With regards to sex differences, additional sex-stratified analyses (Appendix 1) indicate potential differential associations between JDCS model variables and energy balance-related behaviours for men and women. This was particularly salient for LTPA, where associations appeared 
stronger in male-specific analyses but were not significant in female-specific analyses. It has been previously suggested that men and women may vary in their experiences of work ${ }^{38,39)}$. There was some indication of this in the present study, wherein women were more likely to report high psychological demands compared to men.

\section{Strengths and limitations}

This study adhered to recommendations of previous research, which involved including a measurement of total energy intake from diet, alongside a credentialed operationalisation of LTPA. In doing so, this study was able to consider potential associations between psychosocial work factors and both energy intake and expenditurerelated behaviours ${ }^{32)}$. A further strength was the innovative analysis approach that involved assessing the JDCS model constructs at the subscale level, rather than using composite or global scores, while controlling for sex, age, and other sociodemographic variables. A principal limitation of the study is its cross-sectional design, which prevents assertions of causality. As such, the possibility of reverse causation cannot be ruled out, e.g., the possibility that an employee's ability to participate in LTPA, and/or the extent of their dietary intake could, through unspecified selection processes, influence their exposure to psychosocial work factors. Another limitation related to the design is the timing of the data collection, whereby the psychosocial work factors were measured approximately $2-3 \mathrm{yr}$ after the outcome measures. While this discrepancy was handled to some degree in the analyses by ensuring participants worked in the same workplaces for at least $4 \mathrm{yr}$ (mean $16.10 \mathrm{yr}$ ), persons experiencing severe conditions at work may have been more likely to leave in the interim, reducing the generalisability of our results and suggesting that they may be conservative estimates. Nonetheless, there is some evidence to suggest that psychosocial work factors (or perceptions of them) appear relatively stable over an extended period of time ${ }^{63)}$. The precision of our estimates would likely have been improved by including additional factors, such as motivation or health status, which are likely to be associated with both LTPA and dietary energy intake. Another limitation was the limited age range of the participants. Since almost all participants were over the age of 30 at the time of the first telephone interview, it is not clear how our results may generalise to younger employees.

The dietary energy intake $(\mathrm{kJ} / \mathrm{d})$ values for participants in the present study suggest under-reporting of dietary intake may have occurred. Men reported higher daily energy intake $($ mean $=9,006 \mathrm{~kJ} / \mathrm{d})$ compared to women (mean=7,942 kJ/d) (Table 2). However, despite the majority of participants classified as overweight or obese, the average reported dietary energy intake values for these participants are lower than the recommended daily intake for men $(10,700-11,300 \mathrm{~kJ} / \mathrm{d})$ and women $(8,700 \mathrm{~kJ} / \mathrm{d})$ of typical height with a healthy BMI $\left(22.0 \mathrm{~kg} / \mathrm{m}^{2}\right)$ and mostly sedentary activity levels ${ }^{42,64)}$. Such under-reporting is common when using food frequency questionnaires ${ }^{55)}$, and overweight or obese persons may be more likely to underreport ${ }^{65}$. Nonetheless, since the majority of participants in the present study were overweight or obese, these biases may be generally systematic, so relative differences can still be observed.

Another limitation related to the measurement of dietary intake in the present study may be the focus on quantity of dietary energy intake (i.e., $\mathrm{kJ} / \mathrm{d}$ ), and not quality of dietary intake (e.g., macronutrient composition). Previous research suggests that dietary quality (i.e., types of foods and beverages consumed) may influence dietary quantity (i.e., total energy intake) ${ }^{66)}$. Although energy is the same, regardless of the macronutrient quality of the food source, some foods types (e.g., sweet, highly processed snacks) may be less satiating (i.e., less satisfying) than others, which may lead to over-consumption ${ }^{66)}$. As such, since dietary quality may be associated with total energy intake, future research may benefit from considering the quality of dietary intake alongside quantity of energy intake.

\section{Conclusions}

The exploration of the JDCS model at the subscale level has identified several unique associations with two important health behaviours: LTPA and dietary energy intake $(\mathrm{kJ} / \mathrm{d})$, which may underpin the potential association between work stress and overweight and obesity. The positive association between skill discretion and LTPA (i.e., higher levels of skill discretion, greater likelihood of LTPA participation) was the single most consistent association observed in the present study. This finding, combined with an earlier finding that skill discretion was negatively associated with indicators of obesity (i.e., higher levels of skill discretion, smaller BMI and waist circumference) ${ }^{32)}$, suggests interventions to increase skill discretion may result in increased LTPA (proximal factor), and in time this may reduce levels of overweight and obesity (distal factor). Furthermore, older employees may comprise a priority group for intervention, since increasing age was also associated with reduced likelihood of LTPA participation. Male employees may also benefit most from an increase 
in skill discretion, since male-specific analyses (Appendix 1) suggested stronger associations between skill discretion and LTPA, compared to unisex analyses.

To a lesser extent, decision authority was negatively associated with daily energy intake $(\mathrm{kJ} / \mathrm{d})$ from diet (i.e., higher levels of decision authority, reduced likelihood of being in high $\mathrm{kJ} /$ day group). However, potential measurement error for diet may inhibit the validity of these observations. Coworker support was positively associated with dietary energy intake $(\mathrm{kJ} / \mathrm{d})$ (i.e., higher levels of coworker support, increased likelihood of being in high $\mathrm{kJ} / \mathrm{d}$ group). While this counterintuitive observation challenges the traditional perspective that support has a protective function, it is consistent with the findings of a previous study ${ }^{44)}$.

Findings of the present study affirm the importance of controlling for the effects of sex and age in studies of this nature. Age appeared to be directly and negatively related to LTPA participation, while sex-specific analyses (Appendix 1) suggested relationships between JDCS model components, LTPA and dietary energy intake $(\mathrm{kJ} /$ d) may vary by sex. Notably, the positive association between skill discretion and LTPA participation appeared more pronounced in male-specific analyses compared to the main unisex analyses. Future research with a greater sample size would be better powered to more effectively explore these sex differences. Novel findings from the present study should encourage further exploration of the unique associations between JDCS subscales and other health outcomes. Consideration of the JDCS model at the subscale level enables the evaluation of more intricate relationships and could uncover uncharted opportunities to improve employee health and wellbeing.

\section{Acknowledgements}

This research was supported in part by grants from the Australian Research Council (Grants LP0990065 and LP0455737). This manuscript has been reviewed for scientific content and consistency of data interpretation by Chief Investigators of the North West Adelaide Health Study (NWAHS). The NWAHS team are most grateful for the generosity of the cohort participants in the giving of their time and effort to the study. The NWAHS team are also appreciative of the work of the clinic, recruiting and research support staff for their substantial contribution to the success of the study. The authors wish to thank Ms Alicia Montgomerie and Ms Janet Grant for their assistance in preparing the dataset.

\section{References}

1) Flegal KM, Carroll MD, Kit BK, Ogden CL (2012) Prevalence of obesity and trends in the distribution of body mass index among US adults, 1999-2010. JAMA 307, 491-7. [Medline] [CrossRef]

2) Ng M, Fleming T, Robinson $\mathrm{M}$, Thomson B, Graetz N, Margono C, Mullany EC, Biryukov S, Abbafati C, Abera SF, Abraham JP, Abu-Rmeileh NME, Achoki T, AlBuhairan FS, Alemu ZA, Alfonso R, Ali MK, Ali R, Guzman NA, Ammar W, Anwari P, Banerjee A, Barquera S, Basu S, Bennett DA, Bhutta Z, Blore J, Cabral N, Nonato IC, Chang JC, Chowdhury R, Courville KJ, Criqui MH, Cundiff DK, Dabhadkar KC, Dandona L, Davis A, Dayama A, Dharmaratne SD, Ding EL, Durrani AM, Esteghamati A, Farzadfar F, Fay DFJ, Feigin VL, Flaxman A, Forouzanfar MH, Goto A, Green MA, Gupta R, HafeziNejad N, Hankey GJ, Harewood HC, Havmoeller R, Hay S, Hernandez L, Husseini A, Idrisov BT, Ikeda N, Islami F, Jahangir E, Jassal SK, Jee SH, Jeffreys M, Jonas JB, Kabagambe EK, Khalifa SEAH, Kengne AP, Khader YS, Khang YH, Kim D, Kimokoti RW, Kinge JM, Kokubo Y, Kosen S, Kwan G, Lai T, Leinsalu M, Li Y, Liang X, Liu S, Logroscino G, Lotufo PA, Lu Y, Ma J, Mainoo NK, Mensah GA, Merriman TR, Mokdad AH, Moschandreas J, Naghavi M, Naheed A, Nand D, Narayan KMV, Nelson EL, Neuhouser ML, Nisar MI, Ohkubo T, Oti SO, Pedroza A, Prabhakaran D, Roy N, Sampson U, Seo H, Sepanlou SG, Shibuya K, Shiri R, Shiue I, Singh GM, Singh JA, Skirbekk V, Stapelberg NJC, Sturua L, Sykes BL, Tobias M, Tran BX, Trasande L, Toyoshima H, van de Vijver S, Vasankari TJ, Veerman JL, Velasquez-Melendez G, Vlassov VV, Vollset SE, Vos T, Wang C, Wang X, Weiderpass E, Werdecker A, Wright JL, Yang YC, Yatsuya H, Yoon J, Yoon SJ, Zhao Y, Zhou M, Zhu S, Lopez AD, Murray CJL, Gakidou E (2014) Global, regional, and national prevalence of overweight and obesity in children and adults during 1980-2013: a systematic analysis for the Global Burden of Disease Study 2013. Lancet 384, 766-81. [Medline] [CrossRef]

3) Australian Bureau of Statistics Australian Health Survey: First Results, 2014-15; Overweight and Obesity. http://www.abs.gov.au/ausstats/abs@.nsf/Lookup/ by\%20Subject/4364.0.55.001 2014-15 Main\%20 Features Overweight $\% 20$ and $\% 20$ obesity $\sim 22$. Accessed July 7, 2017.

4) World Health Organization. Overweight and Obesity, Fact sheet $\mathrm{N}^{\circ} 311$. http://www.who.int/mediacentre/factsheets/ fs 311/en/. Accessed July 5, 2017.

5) McArdle WD (2007) Exercise physiology: Energy, nutrition, and human performance, 6th Ed., Lippincott Williams \& Wilkins, Baltimore.

6) Martins LCX, Lopes CS (2013) Rank, job stress, psychological distress and physical activity among military personnel. BMC Public Health 13, 716-716. [Medline] 
[CrossRef]

7) World Health Organization Physical Activity and Adults. http://www.who.int/dietphysicalactivity/factsheet_adults/ en/. Accessed July 5, 2017.

8) Australian Institute of Health and Welfare (2003) The Active Australia survey: A guide and manual for implementation, analysis and reporting, AIHW, Canberra.

9) Montgomerie AM, Chittleborough CR, Taylor AW (2014) Physical inactivity and incidence of obesity among South Australian adults. PLoS One 9, e112693. [Medline] [CrossRef]

10) Swinburn BA, Sacks G, Lo SK, Westerterp KR, Rush EC, Rosenbaum M, Luke A, Schoeller DA, DeLany JP, Butte NF, Ravussin E (2009) Estimating the changes in energy flux that characterize the rise in obesity prevalence. Am J Clin Nutr 89, 1723-8. [Medline] [CrossRef]

11) Prentice A, Jebb S (2004) Energy intake/physical activity interactions in the homeostasis of body weight regulation. Nutr Rev 62, S98-104. [Medline] [CrossRef]

12) Millward DJ (2013) Energy balance and obesity: a UK perspective on the gluttony v. sloth debate. Nutr Res Rev 26, 89-109. [Medline] [CrossRef]

13) Swinburn B (2013) Commentary: physical activity as a minor player in the obesity epidemic: what are the deep implications? Int J Epidemiol 42, 1838-40. [Medline] [CrossRef]

14) Butland B, Jebb S, Kopelman P, McPherson K, Thomas S, Mardell J, Parry V (2007) Foresight: Tackling obesities: Future choices project report, 2nd Ed., Government Office for Science, United Kingdom.

15) Winefield HR (2013) Health psychology in relation to employment. In: Applied topics in health psychology, Caltabiano ML, Ricciardelli LA (Eds.), 158-167, WileyBlackwell, Chichester.

16) Karasek RA, Theorell T (1990) Healthy work: Stress, productivity and the reconstruction of working life, Basic Books, New York.

17) Gordon DR, Schnall PL (2009) Beyond the individual: connecting work environment and health. In: Unhealthy work: causes, consequences, cures, Schnall PL, Dobson M, Rosskam E (Eds.), 1-15, Baywood, New York.

18) Maslach C, Schaufeli WB, Leiter MP (2001) Job burnout. Annu Rev Psychol 52, 397-422. [Medline] [CrossRef]

19) Daniels K, Le Blanc PM, Davis M (2014) The models that made job design. In: An introduction to contemporary work psychology, Peeters M, de Jonge J, Taris T (Eds.), 63-88, Wiley-Blackwell, Chichester.

20) Van der Doef M, Maes S (1999) The Job Demand-Control(Support) model and psychological well-being: a review of 20 years of empirical research. Work Stress 13, 87-114. [CrossRef]

21) Macik-Frey M, Quick JC, Nelson DL (2007) Advances in occupational health: from a stressful beginning to a positive future. J Manage 33, 809-40.

22) Solovieva S, Lallukka T, Virtanen M, Viikari-Juntura E
(2013) Psychosocial factors at work, long work hours, and obesity: a systematic review. Scand J Work Environ Health 39, 241-58. [Medline] [CrossRef]

23) Karasek RA (1979) Job demands, job decision latitude, and mental strain: implications for job redesign. Adm Sci Q 24, 285-308. [CrossRef]

24) Johnson JV, Hall EM (1988) Job strain, work place social support, and cardiovascular disease: a cross-sectional study of a random sample of the Swedish working population. Am J Public Health 78, 1336-42. [Medline] [CrossRef]

25) Karasek R, Brisson C, Kawakami N, Houtman I, Bongers P, Amick B (1998) The Job Content Questionnaire (JCQ): an instrument for internationally comparative assessments of psychosocial job characteristics. J Occup Health Psychol 3, 322-55. [Medline] [CrossRef]

26) De Araújo TM, Karasek RA (2008) Validity and reliability of the job content questionnaire in formal and informal jobs in Brazil. SJWEH Suppl 34, 52-59.

27) Courvoisier DS, Perneger TV (2010) Validation of alternative formulations of job strain. J Occup Health 52, 5-13. [Medline] [CrossRef]

28) Smith PM, LaMontagne AD (2015) What is needed to make research on the psychosocial work environment and health more meaningful? Reflections and missed opportunities in IPD debates. Scand J Work Environ Health 41, 594-6. [Medline] [CrossRef]

29) LaMontagne AD (2012) Invited commentary: job strain and health behaviors-developing a bigger picture. Am J Epidemiol 176, 1090-4. [Medline] [CrossRef]

30) Siegrist J, Rödel A (2006) Work stress and health risk behavior. Scand J Work Environ Health 32, 473-81. [Medline] [CrossRef]

31) Hellerstedt WL, Jeffery RW (1997) The association of job strain and health behaviours in men and women. Int $\mathrm{J}$ Epidemiol 26, 575-83. [Medline] [CrossRef]

32) Bean CG, Winefield HR, Sargent C, Hutchinson AD (2015) Differential associations of job control components with both waist circumference and body mass index. Soc Sci Med 143, 1-8. [Medline] [CrossRef]

33) Mansell A, Brough P (2005) A comprehensive test of the job demands-control interaction: comparing two measures of job characteristics. Aust J Psychol 57, 103-14. [CrossRef]

34) de Jonge J, Reuvers MM, Houtman IL, Bongers PM, Kompier MA (2000) Linear and nonlinear relations between psychosocial job characteristics, subjective outcomes, and sickness absence: baseline results from SMASH. Study on musculoskeletal disorders, absenteeism, stress, and health. J Occup Health Psychol 5, 256-68. [Medline] [CrossRef]

35) Joensuu M, Kivimäki M, Koskinen A, Kouvonen A, Pulkki-Råback L, Vahtera J, Virtanen M, Väänänen A (2012) Differential associations of job control components with mortality: a cohort study, 1986-2005. Am J Epidemiol 175, 609-19. [Medline] [CrossRef]

36) Joensuu M, Kivimäki M, Koskinen A, Kouvonen A, 
Pulkki-Råback L, Vahtera J, Virtanen M, Väänänen A (2012) Response to invited commentary: Joensuu et al. respond to "Structure and context matters". Am J Epidemiol 175, 625-6. [Medline] [CrossRef]

37) Joensuu M, Kivimäki M, Pentti J, Virtanen M, Väänänen A, Vahtera J (2014) Components of job control and mortality: the Finnish Public Sector Study. Occup Environ Med 71, 536-42. [Medline] [CrossRef]

38) Evans O, Steptoe A (2002) The contribution of genderrole orientation, work factors and home stressors to psychological well-being and sickness absence in maleand female-dominated occupational groups. Soc Sci Med 54, 481-92. [Medline] [CrossRef]

39) Artazcoz L, Borrell C, Cortès I, Escribà-Agüir V, Cascant L (2007) Occupational epidemiology and work related inequalities in health: a gender perspective for two complementary approaches to work and health research. J Epidemiol Community Health 61 Suppl 2, ii39-45. [Medline] [CrossRef]

40) Tchernof A, Després JP (2013) Pathophysiology of human visceral obesity: an update. Physiol Rev 93, 359-404. [Medline] [CrossRef]

41) Chodzko-Zajko WJ, Proctor DN, Fiatarone Singh MA, Minson CT, Nigg CR, Salem GJ, Skinner JS, American College of Sports Medicine (2009) American college of sports medicine position stand. Exercise and physical activity for older adults. Med Sci Sports Exerc 41, 1510 30. [Medline] [CrossRef]

42) National Health and Medical Research Council [NHMRC] (2006) Nutrient reference values for Australia and New Zealand: Including recommended dietary intakes., Australian Government, Department of Health and Ageing, National Health and Medical Research Council, Canberra.

43) Choi B, Schnall PL, Yang H, Dobson M, Landsbergis P, Israel L, Karasek R, Baker D (2010) Psychosocial working conditions and active leisure-time physical activity in middle-aged us workers. Int J Occup Med Environ Health 23, 239-53. [Medline] [CrossRef]

44) Kawakami N, Tsutsumi A, Haratani T, Kobayashi F, Ishizaki M, Hayashi T, Fujita O, Aizawa Y, Miyazaki S, Hiro H, Masumoto T, Hashimoto S, Araki S (2006) Job strain, worksite support, and nutrient intake among employed Japanese men and women. J Epidemiol 16, 79-89. [Medline] [CrossRef]

45) Adam TC, Epel ES (2007) Stress, eating and the reward system. Physiol Behav 91, 449-58. [Medline] [CrossRef]

46) Stewart-Knox BJ (2014) Eating and stress at work: the need for public health promotion intervention and an opportunity for food product development? Trends Food Sci Technol 35, 52-60. [CrossRef]

47) Grant JF, Chittleborough CR, Taylor AW, Dal Grande E, Wilson DH, Phillips PJ, Adams RJ, Cheek J, Price K, Gill T Ruffin RE, North West Adelaide Health Study Team (2006) The North West Adelaide Health Study: detailed methods and baseline segmentation of a cohort for selected chronic diseases. Epidemiol Perspect Innov 3, 4. [Medline] [CrossRef]

48) Grant JF, Taylor AW, Ruffin RE, Wilson DH, Phillips PJ, Adams RJ, Price K, North West Adelaide Health Study Team (2009) Cohort Profile: The North West Adelaide Health Study (NWAHS). Int J Epidemiol 38, 1479-86. [Medline] [CrossRef]

49) Brown WJ, Burton NW, Marshall AL, Miller YD (2008) Reliability and validity of a modified self-administered version of the Active Australia physical activity survey in a sample of mid-age women. Aust N Z J Public Health 32, 535-41. [Medline] [CrossRef]

50) Brown WJ, Trost SG, Bauman A, Mummery K, Owen N (2004) Test-retest reliability of four physical activity measures used in population surveys. J Sci Med Sport 7, 205-15. [Medline] [CrossRef]

51) National Food Authority (1995) NUTTAB95: Nutrient data table for use in Australia, National Food Authority, Canberra.

52) Giles GG, Ireland PD (1996) Dietary questionnaire for epidemiological studies (Version 2), Cancer Council Victoria, Melbourne.

53) Hodge A, Patterson AJ, Brown WJ, Ireland P, Giles G (2000) The Anti Cancer Council of Victoria FFQ: relative validity of nutrient intakes compared with weighed food records in young to middle-aged women in a study of iron supplementation. Aust N Z J Public Health 24, 576-83. [Medline] [CrossRef]

54) Xinying PX, Noakes M, Keogh J (2004) Can a food frequency questionnaire be used to capture dietary intake data in a 4 week clinical intervention trial? Asia Pac J Clin Nutr 13, 318-23. [Medline]

55) Willett W (2013) Food frequency methods. In: Nutritional epidemiology, 3rd Ed., Willett W (Ed.), 70-95, Oxford University Press, New York.

56) Karasek RA (1985) Job Content Questionnaire and user's guide (Revision 1.1), University of Massachusetts, Lowell.

57) Australian Bureau of Statistics Australian and New Zealand Standard Classification of Occupations, 1st Ed., 1st Rev., June 2009. http://www.abs.gov.au/AUSSTATS/abs@.nsf/ allprimarymainfeatures/E8A05691E35F4376CA257B9500 138A52?opendocument. Accessed July 7, 2017.

58) Kivimäki M, Singh-Manoux A, Nyberg S, Jokela M, Virtanen M (2015) Job strain and risk of obesity: systematic review and meta-analysis of cohort studies. Int J Obes 39, 1597-600. [Medline] [CrossRef]

59) Nyberg ST, Heikkilä K, Fransson EI, Alfredsson L, De Bacquer D, Bjorner JB, Bonenfant S, Borritz M, Burr H, Casini A, Clays E, Dragano N, Erbel R, Geuskens GA, Goldberg M, Hooftman WE, Houtman IL, Jöckel KH, Kittel F, Knutsson A, Koskenvuo M, Leineweber C, Lunau T, Madsen IE, Hanson LL, Marmot MG, Nielsen ML, Nordin M, Oksanen T, Pentti J, Rugulies R, Siegrist J, Suominen S, Vahtera J, Virtanen M, Westerholm P, Westerlund H, Zins M, Ferrie JE, Theorell T, Steptoe A, Hamer M, Singh-Manoux 
A, Batty GD Kivimäki M, IPD-Work Consortium (2012) Job strain in relation to body mass index: pooled analysis of 160000 adults from 13 cohort studies. J Intern Med 272, 65-73. [Medline] [CrossRef]

60) Eller NH, Netterstrøm B, Gyntelberg F, Kristensen TS, Nielsen F, Steptoe A, Theorell T (2009) Work-related psychosocial factors and the development of ischemic heart disease: a systematic review. Cardiol Rev 17, 83-97. [Medline] [CrossRef]

61) André-Petersson L, Engström G, Hedblad B, Janzon L, Rosvall M (2007) Social support at work and the risk of myocardial infarction and stroke in women and men. Soc Sci Med 64, 830-41. [Medline] [CrossRef]

62) De Bacquer D, Pelfrene E, Clays E, Mak R, Moreau M, de Smet P, Kornitzer M, De Backer G (2005) Perceived job stress and incidence of coronary events: 3-year follow-up of the Belgian Job Stress Project cohort. Am J Epidemiol 161, 434-41. [Medline] [CrossRef]
63) Åhlin JK, Westerlund H, Griep Y, Magnusson Hanson LL (2018) Trajectories of job demands and control: risk for subsequent symptoms of major depression in the nationally representative Swedish Longitudinal Occupational Survey of Health (SLOSH). Int Arch Occup Environ Health 91, 263-72. [Medline] [CrossRef]

64) Australian Bureau of Statistics Australian Health Survey: Updated Results, 2011-12; Height and Weight. http://www. abs.gov.au/ausstats/abs@.nsf/0/E11CED5FB86D178ACA2 57AA30014C059?opendocument. Accessed July 7, 2017.

65) Heitmann BL, Lissner L (1995) Dietary underreporting by obese individuals - is it specific or non-specific? BMJ 311, 986-9. [Medline] [CrossRef]

66) Mozaffarian D, Hao T, Rimm EB, Willett WC, Hu FB (2011) Changes in diet and lifestyle and long-term weight gain in women and men. N Engl J Med 364, 2392-404. [Medline] [CrossRef] 


\section{Appendix 1. Sex-stratified analyses}

\section{Leisure-time physical activity: Male-specific analyses}

For men, generally the same associations observed for unisex analyses (Tables 3 and 4) persisted in sex-specific analyses, but with greater ORs and the additional observation of two male-specific associations. Male employees with higher age (yr) had a reduced likelihood of being in the 'sufficient activity' group (compared to 'no activity' group) for LTPA definition $1(\mathrm{OR}=0.92 ; 95 \% \mathrm{CI}=0.87-0.98)$, and definition $2(\mathrm{OR}=0.92 ; 95 \% \mathrm{CI}=0.87-0.98)$. Male employees with higher age (yr) also had a reduced likelihood of being in the 'activity but not sufficient' group (compared to 'no activity' group) for LTPA definition 1 ( $\mathrm{OR}=0.92 ; 95 \% \mathrm{CI}=0.87-0.98)$, and definition $2(\mathrm{OR}=0.92 ; 95 \% \mathrm{CI}=0.87-0.98)$. Male employees reporting scores in the highest tertile of skill discretion (compared to the lowest tertile) had a greater likelihood of being in the 'sufficient activity' group (compared to 'no activity' group) for LTPA definition 1 (OR=4.79; 95\% $\mathrm{CI}=1.12-20.40)$, and definition $2(\mathrm{OR}=5.21 ; 95 \% \mathrm{CI}=1.19-22.81)$. Male employees reporting scores in the highest tertile of skill discretion (compared to the lowest tertile) also had a greater likelihood of being in the 'activity but not sufficient' group (compared to 'no activity' group) for LTPA definition $1(\mathrm{OR}=15.26$; 95\% $\mathrm{CI}=3.14-74.27)$, and definition 2 (OR=9.49; $95 \% \mathrm{CI}=2.14-42.11$ ). Male employees reporting scores in the middle tertile of skill discretion (compared to the lowest tertile) also had a greater likelihood of being in the 'activity but not sufficient' group (compared to 'no activity' group) for LTPA definition $1(\mathrm{OR}=3.62 ; 95 \% \mathrm{CI}=1.24-10.59)$, but this observation was no longer significant for definition $2(\mathrm{OR}=2.67$; $95 \% \mathrm{CI}=0.99-7.16)$ as it was in unisex analyses.

Male-specific associations, not observed in unisex or female-specific analyses, comprised a potentially curvilinear association between decision authority and LTPA definition 1 (but not definition 2), whereby male employees reporting scores in the middle tertile of decision authority (compared to the lowest tertile) had a reduced likelihood (OR=0.29; $95 \% \mathrm{CI}=0.09-0.93$ ) of being in the 'activity but not sufficient' group (compared to 'no activity' group). The second malespecific association suggests male employees reporting above median supervisor support (social support) had a reduced likelihood ( $\mathrm{OR}=0.25 ; 95 \% \mathrm{CI}=0.07-0.88)$ of being in the 'activity but not sufficient' group (compared to 'no activity' group) for LTPA definition 1 , but not definition 2 . The model fit for male-specific analyses was statistically significant for both LTPA definition $1, \chi^{2}(24, N=213)=47.58, p=0.003$; and definition $2, \chi^{2}(24, N=213)=46.74, p=0.004$. Pseudo $R^{2}$ indicators suggest, for men, the full adjusted models as a whole explained between $20.0 \%$ (Cox and Snell $R^{2}$ ) and $23.1 \%$ (Nagelkerke $R^{2}$ ) of variance in LTPA status for definition 1, and between 19.7\% (Cox and Snell $R^{2}$ ) and 22.6\% (Nagelkerke $R^{2}$ ) of variance in LTPA status for definition 2.

\section{Leisure-time physical activity: Female-specific analyses}

For women, none of the associations with LTPA observed in unisex analyses persisted in sex-specific analyses. A potential female-specific negative association was observed between work hours (h per wk) and LTPA, whereby longer working hours may be associated with reduced likelihood for being in the 'activity but not sufficient' group (compared to 'no activity' group) - this was consistent across both LTPA definition $1(\mathrm{OR}=0.96$; 95\% $\mathrm{CI}=0.93-1.00)$, and definition $2(\mathrm{OR}=0.97 ; 95 \% \mathrm{CI}=0.94-1.00)$. However, the model fit for the female-specific analyses was not significant for either LTPA definition $1, \chi^{2}(24, N=220)=24.03, p=0.460$; or definition $2, \chi^{2}(24, N=220)=23.13, p=0.512$. As such, the potential female-specific observation between work hours (hours per week) and LTPA should be interpreted with caution.

\section{Daily energy intake $(\mathrm{kJ} / \mathrm{d})$ from diet: Male-specific analyses}

For men, two of the associations observed in unisex analyses persisted in sex-specific analyses. Male employees reporting higher coworker support (above median) had a greater likelihood ( $\mathrm{OR}=2.89 ; 95 \% \mathrm{CI}=1.06-7.92)$ of being in the 'high kJ/d' tertile (compared to 'low kJ/d' tertile). Furthermore, male employees reporting less than the sample median household income (up \$80,000 Australian dollars), had a greater likelihood ( $\mathrm{OR}=2.99 ; 95 \% \mathrm{CI}=1.39-6.45$ ) of being in the 'high kJ/d' tertile (compared to 'low kJ/d' tertile). However, the model fit for male-specific analyses was not significant for daily energy intake $(\mathrm{kJ} / \mathrm{d})$ from diet, $\chi^{2}(24, N=205)=22.97, p=0.522$. As such, these potential male-specific observations between regression variables and daily energy intake $(\mathrm{kJ} /$ day) from diet should be interpreted with caution. 


\section{Daily energy intake (kJ/d) from diet: Female-specific analyses}

For women, none of the associations with daily energy intake $(\mathrm{kJ} / \mathrm{d})$ from diet observed in unisex analyses remained statistically significant $(p<0.05)$ in sex-specific analyses. Nonetheless, two female-specific associations were observed. For female employees, blue-collar workers had a reduced likelihood ( $\mathrm{OR}=0.19 ; 95 \% \mathrm{CI}=0.05-0.76)$ of being in the 'middle $\mathrm{kJ} / \mathrm{d}$ ' tertile (compared to 'low $\mathrm{kJ} / \mathrm{d}$ ' tertile). Furthermore, a negative association was observed between daily energy intake $(\mathrm{kJ} / \mathrm{d})$ from diet and work hours (h per wk), whereby female employees who worked longer hours had a reduced likelihood ( $\mathrm{OR}=0.97 ; 95 \% \mathrm{CI}=0.94-1.00)$ of being in the 'high $\mathrm{kJ} / \mathrm{d}$ ' tertile (compared to 'low $\mathrm{kJ} / \mathrm{d}$ ' tertile). The model fit for female-specific analyses was significant for daily energy intake $(\mathrm{kJ} / \mathrm{d})$ from diet, $\chi^{2}(24, N=204)=41.77, p=0.014$. Pseudo $R^{2}$ indicators suggest the full adjusted models as a whole explained between 18.5\% (Cox and Snell $R^{2}$ ) and 20.8\% (Nagelkerke $R^{2}$ ) of variance in daily energy intake $(\mathrm{kJ} / \mathrm{d})$ from diet for women. 